\title{
Outcomes of first versus third kidney transplantations: propensity score matching and paired subgroup analysis-a single-centre experience
}

\author{
Gábor Telkes ${ }^{1}$ (D) $\cdot$ László Piros $^{1}$ (D) József Szabó ${ }^{1} \cdot$ Gergely Huszty $^{1} \cdot$ Katalin Eitler $^{1}$ (]) $\cdot$ László Kóbori $^{1}$ (D)
}

Received: 17 July 2020 / Accepted: 15 December 2020 / Published online: 17 January 2021

(C) The Author(s) 2021

\begin{abstract}
Background In the Eurotransplant, $12.6 \%$ of kidney transplantations are a repeat procedure. Third transplants are significantly more complex than first and second ones. We compared the results of first (PRT) versus third (TRT) transplantations.

Methods Between 2011 and 2016, we performed 779 deceased donor adult kidney transplantations, 14.2\% out of them were second, $2.6 \%$ (20) third, and $0.3 \%$ fourth. We compared the pre-, intra-, and postoperative data, kidney function, and survival rate.

Results Recipients of TRT were younger (53.4 vs. $47.3 p=0.02)$. HCV infection rate $(20 \%, p=0.00)$ is ten times higher. The operation time is longer (132 vs. $152 \mathrm{~min}, p=0.02)$, and delayed graft function is much more frequent $(22.4 \% \mathrm{vs.} 60 \%, p=0.00)$. Induction therapy was given to every TRT ( $7.9 \%$ vs. $100 \%)$, but as a result, the rejection rate was the same ( $15 \%)$. Hospital stay is a week longer. Patient's survival at 1, 3, and 5 years for PRT is $96.4 \%, 93.9 \%$, and $91.2 \%$ and for TRT is $90 \%, 85 \%$, and $78.4 \%$, respectively $(p=0.023)$. TRT's odds ratio of fatal outcome is $4.35(1.5-12.5)$. Graft survival at 1,3 , and 5 years for PRT is $93.1 \%, 91.4 \%$, and $90.3 \%$ and for TRT is $75 \%, 75 \%$, and $75 \%$, respectively $(p=0.020)$. TRT's odds ratio of graft loss is 3.14 (1.1-8.9). Of PRT $85.76 \%$, out of PRT $85.76 \%$, while out of TRT $60 \%$ live with a functioning graft, $\mathrm{p}=0.00149$.

Conclusion In a third transplant, both graft and patient survival are significantly inferior to primer ones. Careful selection is required to minimize the patient risk and graft loss.
\end{abstract}

Keywords Kidney transplantation · Patient survival · Graft survival · Graft loss · Retransplantation · Survival · Mortality, propensity score matching analysis

\begin{tabular}{ll}
\multicolumn{2}{l}{ Abbreviations } \\
ARDS & Acute respiratory distress syndrome \\
ATG & Anti-thymocyte globulin \\
BMI & Body mass index \\
CIT & Cold ischaemic time \\
CMV & Cytomegalovirus \\
CT & Computed tomography \\
DBD & Donation after brain death \\
DCD & Donation after cardiac death \\
DGF & Delayed graft function \\
ECD & Expanded criteria donor
\end{tabular}

Gábor Telkes

telkesdr@gmail.com

1 Department of Transplantation and Surgery, Semmelweis University, VIII. Baross u. 23, Budapest H-1082, Hungary

$\begin{array}{ll}\text { ET } & \text { Eurotransplant } \\ \text { HCV } & \text { Hepatitis C } \\ \text { HLA } & \text { Human leukocyte antigen } \\ \text { HT } & \text { Handling, or "anastomosis" time } \\ \text { KDPI } & \text { Kidney donor profile index } \\ \text { KDRI } & \text { Kidney donor risk index } \\ \text { MA } & \text { Mycophenolic acid } \\ \text { nTRT } & \text { Non-third renal transplant } \\ \text { OR } & \text { Odds ratio } \\ \text { OT } & \text { Operation time } \\ \text { PRA } & \text { Panel-reactive antibodies } \\ \text { PRT } & \text { Primer renal transplant } \\ \text { SCD } & \text { Standard criteria donor } \\ \text { SD } & \text { Standard deviation } \\ \text { sTRT } & \text { Selected third renal transplant } \\ \text { TAC } & \text { Tacrolimus } \\ \text { TRT } & \text { Third renal transplant } \\ \text { US } & \text { Ultrasound }\end{array}$




\section{Introduction}

Despite significant improvements in the last five decades, the real half-life of kidney grafts is still around 8 years, substantially shorter than projected half-lives [1]. Chronic graft failure is still a major problem, and especially younger recipients of the primer graft might need a second or third transplantation. The rate of repeat transplantation was increasing in the USA from 1996 to 2005, reaching $12.4 \%$, while potential retransplant recipients represented $16.1 \%$ of all kidney candidates $[2,3]$.

In the Eurotransplant, $17.9 \%$ of those on the waiting list are listed for repeat kidney transplantation, and $13.7 \%$ of the procedures performed was a repeat one in 2019 (http://statistics. eurotransplant.org).

While mortality after a failing graft is considered to be high, the first retransplantation is associated with significantly reduced mortality rates [4-6].

Moreover, in several papers, the outcome of a second graft has been reported to be similar to the first one [7-9]. Others observed that the graft survivals for repeat deceased donor transplants were all significantly lower; the relative risk of graft loss was 1.18-1.24 [2].

Recipients of a third graft constitute a unique population among kidney patients. Patients are often highly sensitized, have limited surgical options, suffer from comorbidities e.g. atherosclerosis, virologic infections, and all other consequences of previous operations, immunosuppression, and long-lasting dialysis. These patients accumulate several risk factors associated with poor patient and graft outcome [10].

The surgery of these patients is always challenging. Several surgical approaches exist but there is no standard technique [11].

Reported results of third transplantations are a bit inconsistent. Some studies demonstrated a similar survival rate to that of primary transplants, at least for patient survival [10, 12, 13]. However, the majority of the literature agrees on inferior graft survival with a higher complication rate [11, 14-16].

The kidney transplantation program started in 1973 in Hungary, and today there is a constant need for repeat transplantations [17]. Accurate knowledge of prognosis may help in the judicious and responsible use of deceased donor kidneys.

\section{Aims}

The aim of our study was to analyse our results of third transplantations and compare them with primary ones.

\section{Materials and methods}

This is a single-centre, retrospective, observational study from the largest Hungarian kidney transplant centre within the
Eurotransplant community, with an institutional experience of more than 5000 kidney transplants since 1973.

\section{Patients}

Between 2011 and 2016, 779 adult, kidney alone, brain-dead deceased donor transplantations were performed and included. Out of them, $82.9 \%$ (646) were first, $14.2 \%$ (111) second, $2.6 \%$ (20) third, and $0.3 \%$ (2) fourth transplantations.

Nine TRT recipients shared the donor with a first or second recipient. We compared the outcomes of these nine pairs as "selected third" (sTRT) vs. "non-third" (nTRT), as a mixed group of 7 first and 2 second recipients. We have no data about the kidney pair of the other eleven third recipients.

We prospectively registered the pre-, intra-, and postoperative data:

- $\quad$ Sex, age, BMI, ECD, virology

- PRA, HLA mismatch, immunosuppressive therapy, rejection

- Surgical details and complications, hospital stay

- DGF, kidney function, graft, and patient survival. Graft survival was recorded from transplantation to graft failure: graftectomy or return to dialysis. Death censored graft survival was counted.

The end of the observation period is March 2019.

\section{Immunosuppression}

Immunosuppression was given as per protocol. Maintenance therapy generally consists of tacrolimus, mycophenolic acid, and prednisolone triple therapy.

Induction therapy was given to all third and $7.9 \%$ of primer recipients, considering previous immunization, $p=0.000$.

\section{Surgical considerations}

According to our centre policy, we require preoperative pelvic angio-CT to visualize the vascular anatomy of the potential TRT recipient. At least one of the previous grafts has to be removed prior to waitlisting. Removal of the specific kidney graft depends on clinical circumstances. Our centre's preferred site is the right iliac fossa for primer, and if possible, for third transplant as well. Third transplantations were performed by experienced senior transplant surgeons.

\section{Statistics}

For descriptive statistical analysis, mean and median values, standard deviations, and absolute and relative frequencies were calculated. Qualitative data were compared by the Pearson Chi-square test. Quantitative variables were 
compared using Mann-Whitney $U$ or Kruskal-Wallis test. Survival was analysed by the Kaplan-Meier method and compared with log-rank test. A $p$ value of less than 0.05 was considered to be significant. Propensity score matching analysis was performed using logistic regression analysis, and then thirds were matched to primers with a 1:1 matching in propensity scores without replacement. The match tolerance was set to 0.1. Statistics were calculated by TIBCO Software Inc. (2018), Statistica (data analysis software system), version 13 , and by IBM SPSS version 25 .

\section{Results}

\section{Donors}

The demographic data of donors are presented in Table 1. TRT donors were younger (47.4 vs.52); there was no difference in BMI, CMV infection rate, or sex. The CMV infection rate represents Hungarian population data, amounting to $86 \%$ [18].

None of our third recipients received an ECD graft, while this rate is about $34 \%$ for primer grafts.

\section{Recipients}

Recipients' data are presented in Table 2. TRT recipients are significantly younger than PRT recipients, (47.3 years vs. 53.4 years). Third recipients got significantly more HCV ( $20 \%$ vs. $2.1 \%$ ), and slightly more CMV infection. The PRA level was much higher ( $34.4 \%$ vs. $2.5 \%$ ) in the TRT group.

\section{Surgery, postop course, rejection}

Details and exact numbers are presented in Table 3. The cold ischaemic time is the same $(\sim 14-15 \mathrm{~h})$, or even shorter in the TRT group. The whole operative time is significantly longer in TRT (132 vs. $152 \mathrm{~min}$ ) (verified by propensity matching analysis as well), with a significantly shorter handling time (42 vs. $35 \mathrm{~min}$ ).

We did not observe differences in vascular or ureter-related complications, and there were no more lymphoceles. In the TRT group, one arterial thrombosis caused graft loss; in the PRT group, we could save three kidneys out of 19 having

Table 1 Demographics of donors

\begin{tabular}{llll}
\hline Donors & PRT (646) & TRT (20) & $p$ \\
\hline Age, y (SD) & $52.0(11.7)$ & $47.4(9.8)$ & n.s. 0.073 \\
female, \% & 44.7 & 40.0 & n.s. \\
BMI & 26.2 & 25.7 & n.s. \\
CMV IgG pos \% & 82.8 & 80.0 & n.s. \\
ECD, \% & 34 & 0 & 0.01 \\
\hline
\end{tabular}

vascular complications. The follow-up US revealed several perirenal hematomas, but they did not require more reoperation.

There were no differences in acute rejection rate (PRT: $15.9 \%$ vs. TRT: $15 \%$ ).

The DGF rate proved to be much more frequent: $22.4 \%$ in the PRT and $60 \%$ in the TRT group, which is highly significant. In case of TRT, the OR of DGF is $5.2(2.1-12.9)$.

Hospital stay proved to be roughly a week longer (PRT 14.8 vs. TRT 21.4 days); propensity analysis verified the significance.

Out of PRT, $78.2 \%$ got end-to-side uretero-ureteral anastomosis, while in the TRT group, $70 \%$ of recipients received neocystostomy; this difference is highly significant (see Table 4).

\section{Patient survival}

Patient survival at 1, 3, and 5 years for PRT is $96.4 \%, 93.9 \%$, and $91.2 \%$, and for TRT it is $90 \%, 85 \%$, and $78.4 \%$, respectively $(p=0.023)$ (Fig. 1). Propensity score matching analysis reconfirmed the significance of the difference.

In the first 30 days, there were $3(0.46 \%)$ deaths in the PRT and $1(5 \%)$ in the TRT group $(p=0.0014)$. Until March 2019, we lost 56 more patients in the PRT group $\left(\sum: 59\right.$, which is $9.13 \%)$ and 4 more in the TRT group ( $\sum: 5$, which is $\left.25 \%\right)$, resulting in a significant difference $(p=0.01)$.

The OR of a fatal outcome for TRT patient is 3.3 (1.169.4) compared to PRT.

Patient survival at 1,3 , and 5 years for nTRT is $100 \%$ and for sTRT is $77.7 \%, 66.7 \%$, and $66.7 \%(p=0.065)$.

\section{Graft survival}

Death censored graft survival at 1,3 , and 5 years for PRT is $93.1 \%, 91.4 \%$, and $90.3 \%$, and for TRT, it is $75 \%, 75 \%$, and $75 \%$, respectively ( $p=0.020)$ (Fig. 2). Propensity analysis revealed better graft survival for PRT; however, this was not significant.

In the first 30 days, there were $26(4.02 \%)$ graft losses in the PRT and $4(20 \%)$ in the TRT group $(p=0.00069)$. One graft had arterial thrombosis caused by acute accelerated rejection; one had acute irreversible rejection; in the others, ischaemic lesions were observed even though ultrasound showed proper circulation.

We lost one more graft about 4 months later due to acute bacterial nephritis following several reoperations. In the long run, there were no more TRT graft losses.

From 2011 to March 2019, graft loss in surviving patients was $9.6 \%$ in the PRT and $25 \%$ in the TRT group $(p=0.024)$.

The odds ratio of graft loss for TRT recipients is 3.14 (1.18.9) compared to PRT.

Graft survival at 1,3 , and 5 years for nTRT is $100 \%$ and for sTRT is $55.6 \%(p=0.028)$. 
Table 2 Demographics, virology, and immunology of the recipients

\begin{tabular}{|c|c|c|c|c|c|c|}
\hline & \multicolumn{3}{|c|}{ All recipients } & \multicolumn{3}{|c|}{ Paired recipients } \\
\hline & PRT (646) & TRT (20) & $p$ & nTRT (9) & sTRT (9) & $p$ \\
\hline Age, y (SD) & $53.4(12.6)$ & $47.3(9.8)$ & 0.016 & 53.7 & 48.9 & n.s. $(0.27)$ \\
\hline Female, $\%$ & 40.1 & 30,0 & n.s. & 66.7 & 22.2 & n.s. \\
\hline BMI & 26.4 & 25.0 & 0.045 & 27.8 & 26.0 & n.s. \\
\hline $\mathrm{HCV}$ pos, $\%$ & 2.1 & 20.0 & 0.000 & 0 & 11.1 & n.s. \\
\hline CMV IgG pos, $\%$ & 81.5 & 95.0 & n.s. & 62.5 & 100 & n.s. \\
\hline $\begin{array}{l}\text { CMV mismatch donor pos. } \\
\text { Recipient neg. }\end{array}$ & $14.2 \%(92)$ & $5 \%(1)$ & n.s. & $22.2(2)$ & 0 & 0.023 \\
\hline Antigen mismatch & 3.0 & 3.1 & n.s. & 2.4 & 2.8 & n.s. \\
\hline PRA level, $\%$ mean/median & $2.5 / 0.0$ & $34.4 / 44.0$ & 0.0000 & $4.7 / 0$ & $30.0 / 7.0$ & 0.0042 \\
\hline
\end{tabular}

Considered significant if $p<0.05$

Patient and graft losses are summarized in Table 5.

\section{Kidney function}

In the TRT group, the function of surviving kidneys is moderately and continuously inferior (see Table 6).

Comparing the sTRT and nTRT groups, who share the same donor, this difference is present, but it does not reach statistical significance either (see Fig. 3).

\section{Discussion}

\section{Donors}

We did not perform any TRT from an ECD. We acknowledge that a selection bias is likely to exist at that point, favouring the TRT group. This practice is justified by the observation of
Miles et al.: The survival of ECD retransplant recipients was not different from those remaining on dialysis [19]. The quality of kidneys used for TRT is the same or even better than the quality of those used for PRT $[3,16]$.

\section{Recipients}

Our rate of TRT, $2.6 \%$, belongs into the upper range according to published data, varying from $1-1.4 \%[16,20]$ to 2.4 $2.9 \%[10,14]$.

There were no really obese patients in our TRT group. A selection bias might exist at that point, too; a real obese candidate (BMI > 35) would be refused, as obesity poses a significant risk of surgical complications [21-23].

Many centres have observed that TRT patients are younger $[2,3,14,16,20]$. Third recipients at a younger age already have a long, chronic medical history. These repeated Uremia-dialysisimmunosuppression-surgery sequences obviously alter the

Table 3 Surgical details and postop. course

\begin{tabular}{|c|c|c|c|c|c|c|}
\hline & \multicolumn{3}{|l|}{ All recipients } & \multicolumn{3}{|c|}{ Paired recipients } \\
\hline & PRT & TRT & $p$ & nTRT & sTRT & $p$ \\
\hline CIT (h) & 14.7 (SD: 4.3) & $14.4(\mathrm{SD}: 4.8)$ & n.s. & 14.9 & 12.8 & n.s. \\
\hline HT (min.) & 42 (SD: 17) & 35 (SD: 13) & 0.02 & 38 & 36 & n.s. \\
\hline OT (min.) & 132 (SD: 40) & 152 (SD: 37) & 0.02 & 118 & 142 & n.s. \\
\hline Stent use \% & 13.3 & 25.0 & n.s. & 11.1 & 11.1 & n.s. \\
\hline DGF $\%$ & 22.4 & 60.0 & 0.00009 & 22.2 & 44.4 & n.s. \\
\hline Haematoma $\%$ & 16.6 & 35.0 & 0.031 & 22.2 & 55.6 & n.s. \\
\hline Lymphocele \% & 4.0 & 0 & n.s. & 11.1 & 0 & n.s. \\
\hline Vascular complications $\%$ & 2.94 & 5.0 & n.s. & 0 & 11.1 & n.s. \\
\hline Ureter complications $\%$ & 8.7 & 20.0 & n.s $(0.08)$ & 11.1 & 33.3 & n.s. \\
\hline Reoperations within 30 days, $\%$ & 8.5 & 10.0 & n.s. & 11.1 & 22.2 & n.s. \\
\hline Biopsy \% & 22.4 & 40.0 & n.s. $(0.06)$ & 33.3 & 66.7 & n.s. \\
\hline Acute rejection \% & 15.9 & 15.0 & n.s. & 22.2 & 22.2 & n.s. \\
\hline Hospital stay (days) & 14.8 & 21.4 & 0.003 & 11.7 & 28.8 & 0.0213 \\
\hline
\end{tabular}

Considered signficant if $p<0.05$ 
Table 4 Types of ureter anastomosis

\begin{tabular}{llll}
\hline & ureteric & Neocystostomy & $p$ \\
\hline PRT & $78.2 \%(504)$ & $21.7 \%(140)$ & 0.00 \\
TRT & $30 \%(6)$ & $70 \%(14)$ & \\
\hline
\end{tabular}

Considered significant if $p<0.05$

patient's body structure, cardiac and vascular status, etc. [11, 16, $24,25]$. This factor is probably highly underestimated as it is almost impossible to objectify. Kousoulas et al. presented a cut value, 43 years, as an independent risk factor for mortality [26]. Further efforts are to be taken to prevent early graft loss in these young patients with long predicted lifespan.

The rate of HCV positivity in the PRT group is slightly higher than the population-based frequency in Hungary $(0.5-0.7 \%)[27$, 28]. The infection rate reaches a tenfold higher rate in the TRT group, resulting in a highly significant difference.

The PRA level, a marker of prior sensitization, proved to be much higher in the TRT population. This is expected and consistent with all the known literature. Several papers report a trend that a PRA of more than $80 \%$ is associated with poor long-term graft function [15, 20, 29]. In our cohort, we could not demonstrate a significant relationship between the PRA level and the outcome. Out of twenty, only two of our TRT recipients had PRA $>80 \%$, and both are doing well. This remains a controversial area of transplantation.

\section{Surgery, postop course, rejection}

The mean cold ischaemic time is the same for PRT and TRT. Comparing the nTRT and sTRT groups, there is an almost 2-h difference in favour of third transplantations.
TRT needs significantly longer operative time [3, 26, 30].

Surgical opinions vary in the question of previous transplant nephrectomy. Kienzl-Wagner et al. claim it is not necessary at all [25]. Another opinion is that it can be performed in the same setting prior to retransplantation $[15,24,31]$.

Our policy is that at least one of the previous grafts has to be removed prior to waitlisting. We strongly believe that this is rational as both presence and removal might cause unexpected complications. TRT itself is a demanding long operation performed on a comorbid patient, and there is no need for any extension of the procedure.

Another potential surgical challenge is creating ureter anastomosis. The majority of centres perform neocystostomy for TRT patients [20, 25, 32], and uretero-ureteric anastomosis is reserved for technical difficulties [33]. Historically, a specialty of our centre is the creation of end-to-side uretero-ureteral anastomosis [34, 35]. But in the third transplant procedures, the native ureter of the recipient is more likely to be scaring or tight, and because of that, in most of the cases, neocystostomy has been performed. Yet, more ureter complications occurred in TRT than in PRT, not being significant, but seeming to be remarkable clinically.

Induction therapy was given after immunologic consideration in a few cases in PRT and to everyone in the TRT group with the likely result that there was no difference in acute rejection rates. This is important as the negative impact of even a single episode of acute rejection is well documented [20, 36-39]. However, this finding is in contrast with others [3, 12, 20].
Fig. 1 Patient survival PRT vs.

TRT

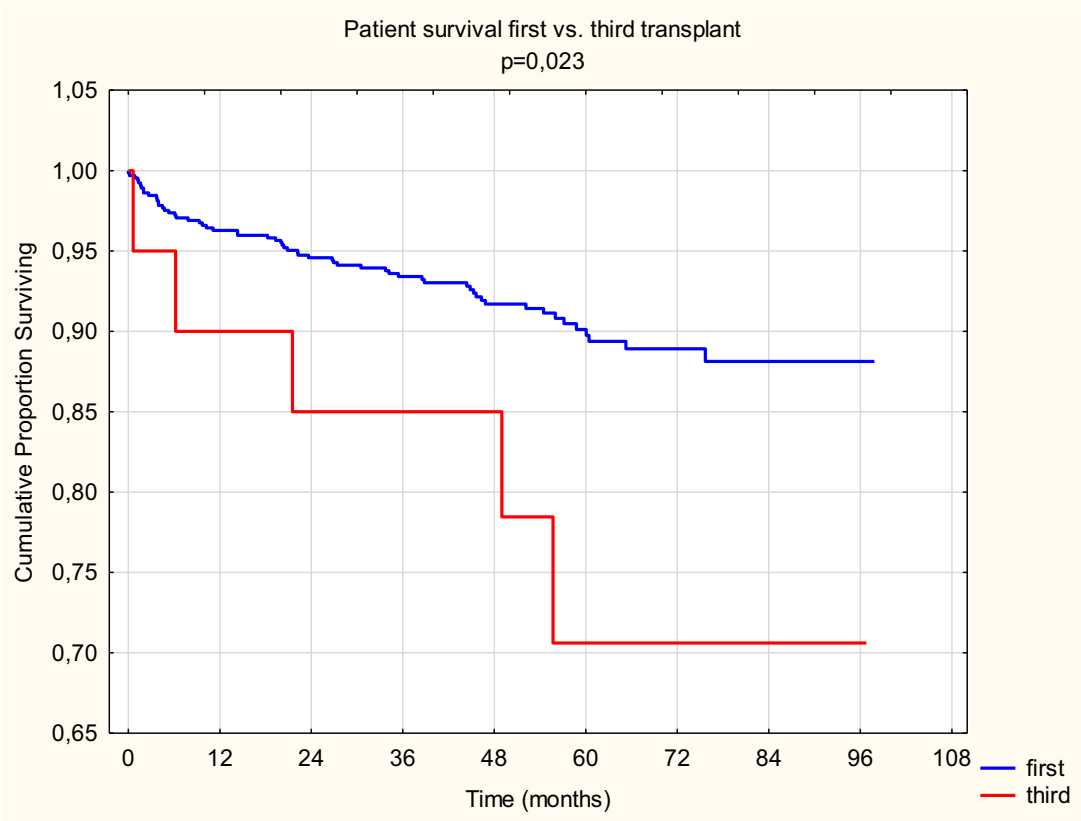


Fig. 2 Graft survival PRT vs. TRT

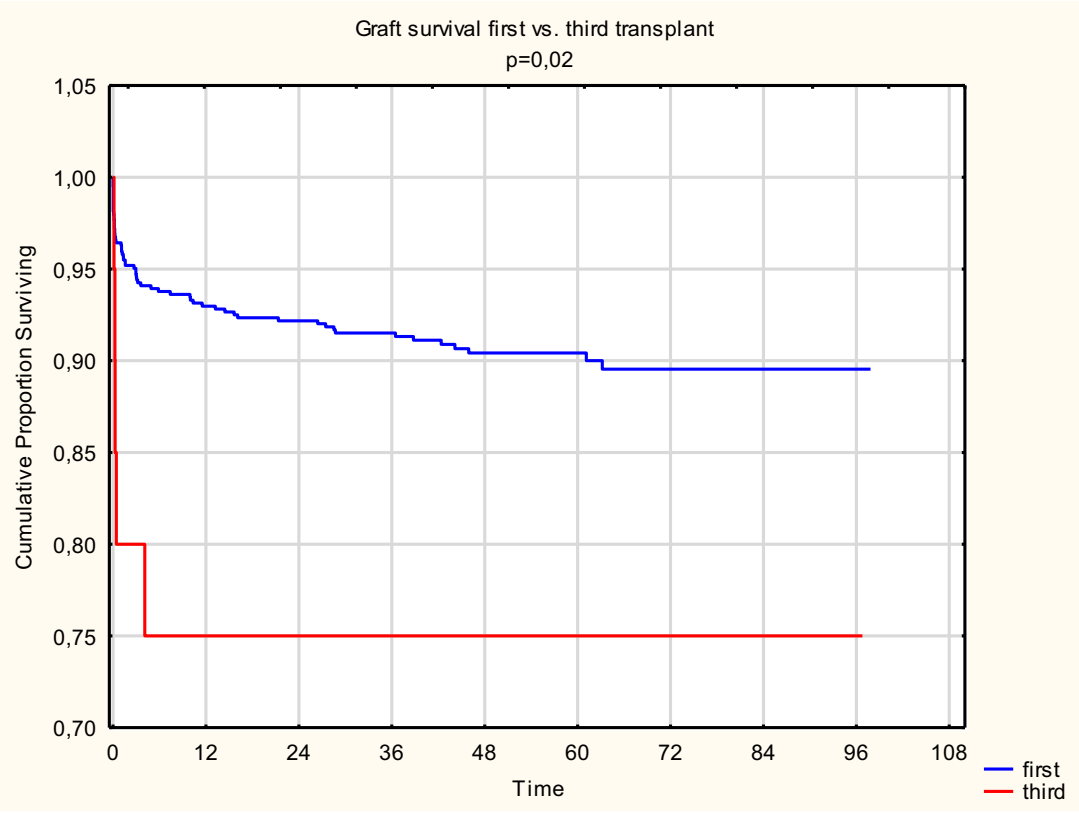

The DGF rate proved to be significantly higher in TRT. Most authors assume that the increased rate of DGF is driven by recipient factors, namely, sensitization, rather than by donor factors [3, 16, 20, 25, 30, 40, 41].

Remarkably more indicative biopsies were obtained in TRT. We do not perform protocol biopsies.

Induction therapy, prolonged DGF, more frequent biopsy, and other factors resulted to a 1-week longer hospital stay, reaching a high significance.

All these factors together count for much higher expenses in case of a third transplantation $[42,43]$.

\section{Outcome}

\section{Patient survival}

Death in the first 30 days occurred in very few cases, due to cardiac failure or pneumonia with sepsis and ARDS.
On the long run, cerebro- and cardiovascular events caused the death of our TRT patients, who are at a higher risk of fatal outcome. Our finding corresponds to the multicentre ET study [14]. Many other groups reported similar patient survival as compared to first and second transplants, but the leading causes of death, cardiovascular events and sepsis, correlate with our findings [3, 10, $12,13,24,25,44]$.

On the other hand, even third transplantation is associated with a significant survival advantage relative to remaining on dialysis, provided that an SCD donor organ was used [4, 6, 11, $16,19]$.

\section{Graft survival}

Graft losses occurred in the first 6 months, and in our paired subpopulation (sTRT vs. nTRT), the same was observed. This early graft loss is likely the cause of inferior graft survival [2,

Table 5 Graft and patient loss

\begin{tabular}{|c|c|c|c|c|c|c|}
\hline & \multicolumn{3}{|c|}{ All recipients } & \multicolumn{3}{|c|}{ Paired recipients } \\
\hline & PRT & TRT & $p$ & nTRT & sTRT & $p$ \\
\hline Graft loss within 30 days $\%$ & 4.02 & 20 & 0.00069 & 0 & 33.3 & n.s. $(0.058)$ \\
\hline Graftectomy within 30 days, $\%$ & 3.25 & 5.0 & n.s. & 0 & 11.1 & n.s. \\
\hline Graft loss total, $\%$ & 9.6 & 25 & 0.02411 & 0 & 44.4 & 0.02334 \\
\hline Death within 30 days, $\%$ & 0.46 & 5.0 & 0.0014 & 0 & 11.1 & n.s. \\
\hline Death total, $\%$ & 9.13 & 25 & 0.01 & 0 & 33.3 & n.s. $(0.058)$ \\
\hline Efficiency (working grafts) \% & 85.76 & 60.0 & 0.00149 & 100 & 44.4 & 0.00851 \\
\hline
\end{tabular}

Considered significant if $p<0.05$ 
Table 6 Postoperative serum creatinine $(\mu \mathrm{mol} / \mathrm{l})$

16, 25, 30, 31]. Assfalg et al. in the ET study observed significantly worse patient and graft survival, and the authors found this issue so pronounced that they question the current policy of repeated retransplantations, especially the forth ones [14]. However, Horovitz et al., who compared the kidneys from paired donors, demonstrated only insignificant differences [3].

We had no TRT graft loss due to surgical reasons. Graft loss occurred as the result of either early rejection or chronic allograft dysfunction, which is in agreement with others [3, $10,20,25,30]$.

We introduced a not too scientific, but practical parameter to assess the efficiency of our labour investment into third transplantations. The rate of working kidneys in living recipients per performed transplantations is much higher following PRT.
TRT and sTRT recipients show a lower GFR until the end of the first post-transplant year. This might have a clinical importance, although mathematically it is not significant.

\section{Summary}

In a third transplant, younger recipients receive a younger, good quality kidney, and still both graft and patient survival are significantly inferior to primer ones. Third kidney transplantations may be performed safely by experienced, senior surgeons, but they represent an intense surgical challenge. The main cause of graft loss is rather immune mediated than surgical. This sensitized patient population requires profound immunosuppression with all its risks and consequences.

Patients are at a high mortality risk receiving a third transplant, but this is probably less than remaining on dialysis. A meticulous patient selection is mandatory with a view to reducing post-transplant mortality. Immunotherapy, postoperative dialysis, and prolonged hospital stay cause remarkable expenses. Further prospective studies should be performed to compare the third transplantation with the continuation of dialysis.

Acknowledgement Open Access funding provided by Semmelweis University. We say special thanks to János Fekete from the Department of Bioinformatics, Semmelweis University, for the statistical help and calculations.
Fig. 3 Kidney function nTRT vs. sTRT

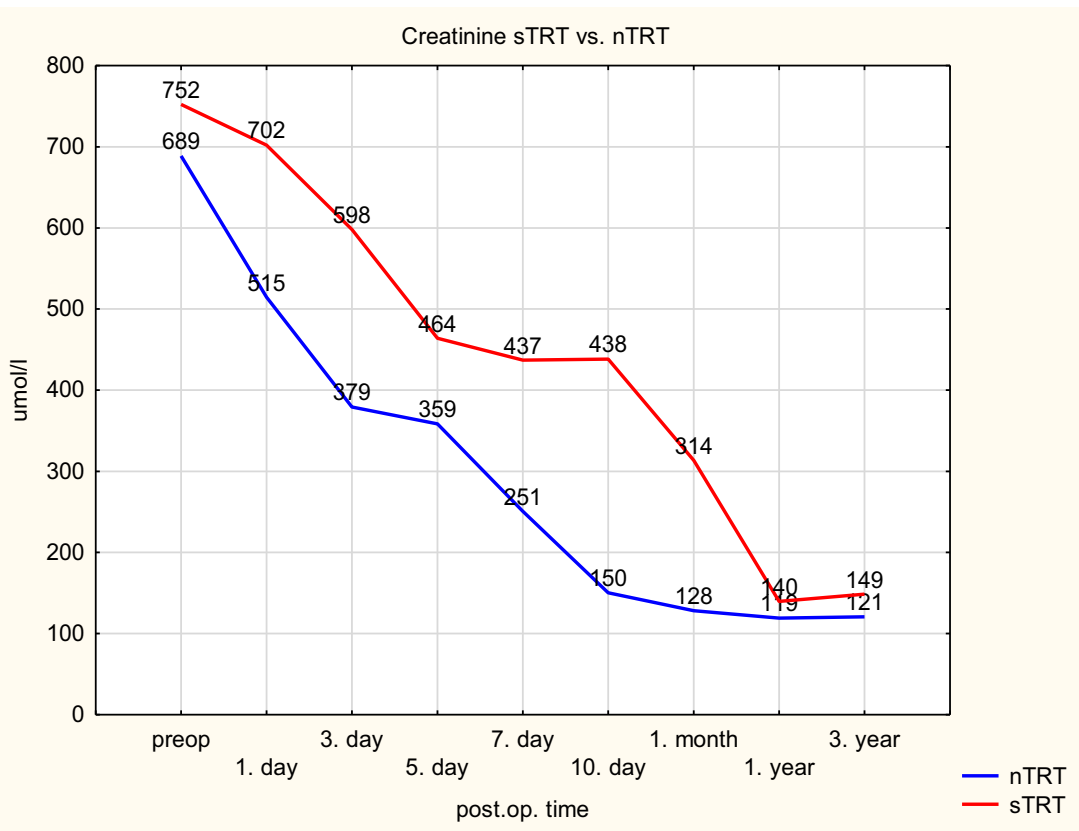


Authors' contributions Each author participated in the transplantations, collection and analysis of data, writing parts of the paper, and approving the final version.

Data availability Data are available at the corresponding author.

\section{Compliance with ethical standards}

Conflict of interest The authors declare that they have no conflict of interest.

Ethics approval Not applicable.

Consent to participate Not applicable.

Consent for publication Not applicable.

Code availability Not applicable.

Open Access This article is licensed under a Creative Commons Attribution 4.0 International License, which permits use, sharing, adaptation, distribution and reproduction in any medium or format, as long as you give appropriate credit to the original author(s) and the source, provide a link to the Creative Commons licence, and indicate if changes were made. The images or other third party material in this article are included in the article's Creative Commons licence, unless indicated otherwise in a credit line to the material. If material is not included in the article's Creative Commons licence and your intended use is not permitted by statutory regulation or exceeds the permitted use, you will need to obtain permission directly from the copyright holder. To view a copy of this licence, visit http://creativecommons.org/licenses/by/4.0/.

\section{References}

1. Meier-Kriesche HU, Schold JD (2004) Kaplan B long-term renal allograft survival: have we made significant progress or is it time to rethink our analytic and therapeutic strategies? Am J Transplant 4(8):1289-1295

2. Magee JC, Barr ML, Basadonna GP, Johnson MR, Mahadevan S, McBride MA, Schaubel DE, Leichtman AB (2007) Repeat organ transplantation in the United States, 1996-2005. Am J Transplant 7(5 Pt 2):1424-1433

3. Horovitz D, Caumartin Y, Warren J, Sheikh AA, Bloch M, Kapoor A, Jevnikar AM, Luke PPW (2009) Outcome of third renal allograft retransplants versus primary transplants from paired donors. Transplantation. 87(8):1214-1220. https://doi.org/10.1097/TP. 0b013e31819f0f5c

4. Ojo A, Wolfe RA, Agodoa LY et al (1998 Dec 27) Prognosis after primary renal transplant failure and the beneficial effects of repeat transplantation: multivariate analyses from the United States renal data system. Transplantation. 66(12):1651-1659

5. McCaughan JA, Patterson CC, Maxwell AP, Courtney AE (2014) Factors influencing survival after kidney transplant failure. Transplant Res 3:18

6. Rao PS, Schaubel DE, Wei G, Fenton SS (2006) Evaluating the survival benefit of kidney retransplantation. Transplantation. 82(5): 669-674

7. Coupel S, Giral-Classe M, Karam G, Morcet JF, Dantal J, Cantarovich D, Blancho G, Bignon JD, Daguin P, Soulillou JP, Hourmant M (2003) Ten-year survival of second kidney transplants: impact of immunologic factors and renal function at 12 months. Kidney Int 64(2):674-680

8. Barocci S, Valente U, Fontana I, Tagliamacco A, Santori G, Mossa M, Ferrari E, Trovatello G, Centore C, Lorenzi S, Rolla D, Nocera A (2009) Long-term outcome on kidney retransplantation: a review of 100 cases from a single center. Transplant Proc 41(4):1156-1158

9. Yeo SM, Kim Y, Kang SS, Park WY, Jin K, Park SB, Park UJ, Kim HT, Cho WH, Han S (2017) Long-term clinical outcomes of kidney re-transplantation. Transplant Proc 49(5):997-1000

10. Loupy A, Anglicheau D, Suberbielle C, Mejean A, Martinez F, Zuber J, Mamzer-Bruneel MF, Kreis H, Thervet E, Thiounn N, Legendre C (2007) Long-term outcome of third kidney transplants. Nephrol Dial Transplant 22(9):2693-2700

11. Halawa A (2012) The third and fourth renal transplant, technically challenging, but still a valid option. Ann Transplant 17(4):125-132

12. Matas AJ, Gillingham KJ, Payne WD et al (1996) A third kidney transplant: cost-effective treatment for end-stage renal disease? Clin Transpl 10(6 Pt 1):516-520

13. Friedersdorff F, Patabendhi S (2016) Busch J et al Outcome of patients after third and fourth kidney transplantation. Urol Int 97(4):445-449

14. Assfalg V, Selig K, Tolksdorf J, Meel M, Vries E, Ramsoebhag AM, Rahmel A, Renders L, Novotny A, Matevossian E, Schneeberger S, Rosenkranz AR, Berlakovich G, Ysebaert D, Knops N, Kuypers D, Weekers L, Muehlfeld A, Rump LC, Hauser I, Pisarski P, Weimer R, Fornara P, Fischer L, Kliem V, Sester U, Stippel D, Arns W, Hau HM, Nitschke M, Hoyer J, Thorban S, Weinmann-Menke J, Heller K, Banas B, Schwenger V, Nadalin S, Lopau K, Hüser N, Heemann U (2020) Repeated kidney re-transplantation - the Eurotransplant experience: a retrospective multicenter outcome analysis. Transpl Int 33(6):617-631

15. Blanco M, Medina J, Gonzalez E, Dominguez M, Rodriguez A, Pamplona M, Andres A, Leiva O, Morales JM (2009) Third kidney transplantation: a permanent medical-surgical challenge. Transplant Proc 41(6):2366-2369

16. Redfield RR, Gupta M, Rodriguez E, Wood A, Abt PL, Levine MH (2015) Graft and patient survival outcomes of a third kidney transplant. Transplantation. 99(2):416-423

17. Perner F, Megyaszai S, Járay J, Faller J, Szécsény A (1974) Successful kidney transplantation in Hungary. Orv Hetil 115(35): 2067-2068

18. Varga M, Gorog D, Kari D et al (2011) Cytomegalovirus seroprevalence among solid organ donors in Hungary: correlations with age, gender, and blood group. Transplant Proc 43(4):1233-1235

19. Miles CD, Schaubel DE, Jia X, Ojo AO, Port FK, Rao PS (2007) Mortality experience in recipients undergoing repeat transplantation with expanded criteria donor and non-ECD deceased-donor kidneys. Am J Transplant 7(5):1140-1147

20. Hagan C, Hickey DP (2003) Little DM a single-center study of the technical aspects and outcome of third and subsequent renal transplants. Transplantation. 75(10):1687-1691

21. Kamdoum Nanfack ML, Bayoud Y, Marchand C, Cholley I, Leon P, Fournier R, Lassere T, Larre S (2015) Is obesity a barrier to kidney transplantation? Prog Urol 25(1):40-46

22. Veasey TM, Fleming JN, Strout SE, Miller R, Pilch NA, Meadows HB, Mardis CR, Mardis BA, Shenvi S, McGillicuddy J, Chavin KD, Baliga P, Taber DJ (2018) Morbid obesity and functional status as predictors of surgical complication after renal transplantation. Am J Surg 215(4):663-668

23. Dabare D, Kassimatis T, Hodson J, Khurram MA, Papadakis G, Rompianesi G, Shaw O, Karydis N, Callaghan C, Olsburgh J, Mamode N, Kessaris N, Loukopoulos I (2019) Outcomes in third and fourth kidney transplants based on the type of donor. Transplantation 103(7):1494-1503

24. Izquierdo L, Peri L, Piqueras M, Revuelta I, Alvarez-Vijande R, Musquera M, Oppenheimer F, Alcaraz A (2010) Third and fourth 
kidney transplant: still a reasonable option. Transplant Proc 42(7): 2498-2502

25. Kienzl-Wagner K, Mark W, Maglione M, Brandacher G, Öllinger R, Margreiter R, Pratschke J, Bösmüller C (2011) Single-center experience with third and fourth kidney transplants. Transpl Int 24(8):780-786

26. Kousoulas L, Vondran FW, Syryca P, Klempnauer J, Schrem H, Lehner F (2015) Risk-adjusted analysis of relevant outcome drivers for patients after more than two kidney transplants. J Transp Secur 2015:712049

27. Barna TK, Ozsvár Z, Szendrényi V, Gál G (1996) Hepatitis C virus antibody in the serum of blood donors. Orv Hetil 137(10):507-511 [Article in Hungarian]

28. Pár A, Pár G (2018) Three decades of the hepatitis $\mathrm{C}$ virus from the discovery to the potential global elimination: the success of translational researches. Orv Hetil 159(12):455-465

29. Hirata M, Terasaki PI (1994) Renal retransplantation. Clin Transpl 419-433

30. Mazzucchi E, Danilovic A, Antonopoulos IM, Piovesan AC, Nahas WC, Lucon AM, Srougi M (2006 Mar 27) Surgical aspects of third and subsequent renal transplants performed by the extraperitoneal access. Transplantation. 81(6):840-844

31. Gutiérrez Baños JL, Rodrigo Calabia E, Rebollo Rodrigo M d H et al (2005) Surgical details and complications from retransplantation into the iliac fossa for third and fourth kidney transplants. Arch Esp Urol 58(2):121-129

32. Nourbala MH, Ghaheri H, Kardavani B (2007) Our experience with third renal transplantation: results, surgical techniques and complications. Int J Urol 14(12):1057-1059

33. Musquera M, Peri LL, Alvarez-Vijande R, Oppenheimer F, GilVernet JM (2010) Alcaraz a Orthotopic kidney transplantation: an alternative surgical technique in selected patients. Eur Urol 58(6): 927-933

34. Perner F, Járay J, Alföldy F, Makó E, Hernády T, Szécsény A (1984) Experiences with ureteroureteral anastomosis in renal transplant: early complications and late results. Transplant Proc 16(5): 1335-1336

35. Perner F, Járay J, Alföldy F et al (1996) The results of 1009 kidney transplantations performed in Hungary. Surg Today 26:561
36. Meier-Kriesche HU, Ojo AO, Hanson JA, Cibrik DM, Punch JD, Leichtman AB, Kaplan B (2000) Increased impact of acute rejection on chronic allograft failure in recent era. Transplantation. 70(7):1098-1100

37. Joseph JT, Kingsmore DB, Junor BJ, Briggs JD, Mun Woo Y, Jaques BC, Hamilton DN, Jardine AG, Jindal RM (2001 Aug) The impact of late acute rejection after cadaveric kidney transplantation. Clin Transpl 15(4):221-227

38. Koo EH, Jang HR, Lee JE, Park JB, Kim SJ, Kim DJ, Kim YG, Oh HY, Huh W (2015) The impact of early and late acute rejection on graft survival in renal transplantation. Kidney Res Clin Pract 34(3): 160-164

39. Benkö T, Halfmann P, Gäckler A, Radünz S, Treckmann JW, Kaiser GM, Hoyer DP (2019) Long-term outcome of third, fourth and fifth kidney transplantation: technical aspects and immunological challenges. Clin Kidney J 12(6):895-900

40. Ghods AJ, Savaj S, Abbasi M, Heidari H (2007) Rokhsatyazdi H The incidence and risk factors of delayed graft function in 689 consecutive living unrelated donor renal transplantation. Transplant Proc 39(4):846-847

41. López-Hoyos M, Fernández-Fresnedo G, Rodrigo E, Ruiz JC, Arias M (2005) Effect of delayed graft function in hypersensitized kidney transplant recipients. Hum Immunol 66(4):371-377

42. Barreto MFC, Dellaroza MSG, Fernandes KBP, Pissinati PSC, Galdino MJQ, Haddad MDCFL (2019) Hospitalization costs and their determining factors among patients undergoing kidney transplantation: a cross-sectional descriptive study. Sao Paulo Med J 137(6):498-504

43. Chaib-Eddour D, Chaib-Eddour H, Malaise J, Mourad M, Squifflet JP (2005) Cost of renal transplant in Belgium. Transplant Proc 37(6):2819-2820

44. Reboux AH, Kamar N, Fort M, Rischmann P, Malavaud B, Cointault O, Abbal M, Durand D, Rostaing L (2005) A third renal transplantation: is it relevant and is it worth it? Transplant Proc 37(10):4199-4202

Publisher's note Springer Nature remains neutral with regard to jurisdictional claims in published maps and institutional affiliations. 